\title{
Editorial
}

\section{The Concept 'Patient Satisfaction' as it Relates to Contemporary Health Care}

\author{
A R M Saifuddin Ekram ${ }^{1}$, Md. Fazlur Rahman ${ }^{2}$
}

Patient satisfaction has become an established indicator of the quality of health care yet, despite the abundance of measurement surveys reported in the literature, there are few theoretical underpinnings for this important concept . A review of the medical literature relating to the term "patient satisfaction" shows little research on the topic in the 1960s and 1970s. However, things began to pick up dramatically in the early 1980s. Between 1980 and 1996, there was a five-fold increase in the number of articles devoted to this topic. Why this increasing interest? Perhaps it was a natural outgrowth of the consumer movement begun in the 1960s and 1970s. Or may be it reflected the maturation of the family medicine research agenda. Equally plausible might be the emerging competitiveness of managed care, which led to using patient satisfaction surveys to distinguish between providers. ${ }^{1}$

The past decade has seen increased attention focused on patient satisfaction; however, there are no universally accepted means of measuring patient satisfaction. A review of recent studies reveals some interesting findings. Satisfaction has been shown to be related directly to patient expectations; however, intuitive physician judgments about patient expectations may not correlate with true expectations. Further, patient satisfaction may not correlate with the level of clinical outcome. Recent advances have changed our understanding of this complex field. ${ }^{2}$
It is worth noting that most patient-satisfaction studies are based on patients' experiences at onetime encounters rather than their experiences over time. In addition, discussions in the literature make it clear that quality of care is not what is being measured in patient surveys. In fact, many surveys intentionally avoid asking patients how they feel about the quality of their care, presumably because patients are not in a position to judge their physician's technical skill. It appears that what's being measured is typically a combination of the patient's expectation before the visit, the patient's experience at the visit and the extent to which the patient experienced a resolution of the symptoms that led him or her to make the visit. ${ }^{3}$

While the literature contains a number of contradictions on the subject of patient satisfaction, it also offers a number of compelling reasons for working to improve satisfaction among our patients. Studies support the idea that patients who get better are (not surprisingly) satisfied with their care. One study, in which researchers followed up with patients three weeks after they were seen, found that most were better, but those who were still symptomatic were still worried, had unmet expectations and had lower satisfaction. ${ }^{4}$ African Americans with type-2 diabetes who were most satisfied with the helpfulness of their physicians and nurses were significantly less likely to use the emergency room. ${ }^{5}$ Patients who reported

1 Professor, Department of Medicine, Rajshahi Medical College, Rajshahi.

2 Professor \& Head, Department of Pathology, Rajshahi Medical College, Rajshahi. 
being treated with dignity and who were involved in decisions were more satisfied and more adherent to their doctor's recommendations. ${ }^{6}$ Patient satisfaction surveys of inpatient physician performance showed an inverse relationship between satisfaction and risk management episodes. $^{7}$

Assessment of patient satisfaction allows doctors/general practitioners to investigate the extent to which their service meets the needs of their client group ${ }^{8}$. Questionnaires that assess specific aspects of service provision will enable the practitioner to identify aspects of the service where patients are less satisfied, and potentially improve these aspects of care ${ }^{9}$. Research has shown that satisfied patients are more likely to follow treatment instructions and medical advice, probably because they are more likely to believe that treatment will be effective ${ }^{10}$. They are also less likely to change doctors and file complaints ${ }^{11}$. It is therefore in the doctors/general practitioner's interest to know the extent of patient satisfaction with service provision ${ }^{12}$.

\section{References}

1. White B. Measuring patient satisfaction: how to do it and why to bother? Fam Pract Manag. 1999; 6(1):40-4. 2.1.

2. Nettleman. Patient satisfaction--what's new? Clin Perform Qual Health Care. 1998; 6(1):33-7.

3. Thiedke C. What Do We Really Know About Patient Satisfaction? Fam Pract Manag. January 2007, Vol. 14, No. 1, pages 33-6.
4. Kroenke $\mathrm{K}$, Jackson JL. Outcome in general medical patients presenting with common symptoms. Fam Pract. 1998; 15:398-403.

5. Gary TL, Maiese EM, Batts-Turner M, Wang NY, Brancati FL. Patient satisfaction, preventive services and emergency room use among AfricanAmericans with type-2 diabetes. Dis Manag. 2005; 8:361-371.

6. Beach MC, Sugarman J, Johnson RL, Arbelaez JJ, Duggan PS, Cooper LA. Do patients treated with dignity report higher satisfaction, adherence and receipt of preventive care? Ann Fam Med. 2005; 3:331-338

7. Stelfox HT, Gandhi TK, Orav EJ, Gustafson ML. The relation of patient satisfaction with complaints against physicians and malpractice lawsuits. Am J Med. 2005; 118:1126-1133.

8. Avis M, Bond M, Arthur A. Satisfying solutions? A review of some unresolved issues in the measurement of patient satisfaction. J Advan Nurs 1995; 22:316-22.

9. Harris LE, Swindle RW, Mungai SM, et al. Measuring patient satisfaction for quality improvement. Med Care 1999; 37:1207-13.

10. Hardy GE, West MA, Hill F. Components and predictors of patient satisfaction. $\mathrm{Br} J$ Health Psychol 1996; 1:65-85.

11. Taylor SE. Health psychology. New York: McGraw Hill, 1995.

12. Woodward CA, Ostbye T, Craighead J, et al. Patient satisfaction as an indicator of quality care in independent health facilities: developing and assessing a tool to enhance public accountability. Am J Med Qual 2000; 15:94-105. 